\title{
VARIAÇÕES SEMÂNTICAS DE VALORAÇÃo EM REINSTANCIAÇÕES PORTUGUESAS E BRASILEIRAS DE THINGS FALL APART E ARROW OF GOD
}

\author{
Célia Maria Magalhães 1 \\ Cliver Gonçalves Dias ${ }^{1}$ \\ -Universidade Federal de Minas Gerais \\ Belo Horizonte, Minas Gerais, Brasil
}

\begin{abstract}
Resumo: Este artigo expande a investigação realizada em Dias (2018), sobre variações semânticas de VALORAÇãO ${ }^{2}$ em traduções brasileiras de dois romances de Chinua Achebe, Things Fall Apart (1994[1959]) e Arrow of God (1969[1964]), para traduções portuguesas destes textos. O objetivo deste artigo é identificar variações semânticas da vaLORAÇão nas retraduções e testar a hipótese da retradução que tem origem em Berman (1990). De acordo com reflexões teóricas neste texto, a tradução de um texto literário seria um ato "incompleto" que só poderia almejar sua completude através das retraduções. Trabalhos empíricos sobre a tradução de textos literários estudam a vALORAÇÃo, descontextualizada do seu significado no desenrolar dos textos, usando a metodologia de análise de corpora. Dias (2018) usa um modelo semântico-discursivo para estudar a tradução como reinstanciação, considerando o desenrolar das narrativas literárias. Neste trabalho, foram usados excertos das reinstanciações portuguesas Tudo se desmorona (2008), de Things fall apart, e A flecha de Deus (1979), de Arrow of God. O estudo utiliza o método de análise da VALORAÇÃo, da semântica-discursiva, para investigar padrões de configurações valorativas de atitude, comprometimento e gradação nos textos selecionados. Os resultados, comparados aos resultados de Dias (2018), sugerem que há variações semânticas entre os
\end{abstract}

${ }^{1}$ Agradecemos ao Conselho Nacional de Pesquisa e Desenvolvimento (CNPq), Projeto PQ 302123/2017-2, pelo financiamento desta pesquisa.

${ }^{2}$ Assim como em Martin e Rose (2007), adota-se o uso do recurso tipográfico "versalete" para os nomes dos sistemas como termos técnicos. 
pares de reinstanciações relativas ao modo de ativação, ao acoplamento e à calibragem, bem como à não reinstanciação de valores ou instanciação de novos valores. Estes resultados sugerem que as duas reinstanciações são paráfrases distintas dos texto-fontes, confirmando a hipótese da retradução.

Palavras-chave: Variações semânticas; VALORAÇ̃̃o; Reinstanciação; Retradução; Things Fall Apart; Arrow of God.

\title{
SEMANTIC VARIATIONS OF APPRAISAL IN PORTUGUESE AND BRAZILIAN RE-INSTANTIATIONS OF THINGS FALL APART AND ARROW OF GOD
}

\begin{abstract}
This article expands the investigation in Dias (2018), on semantic variations of appraisal in Brazilian translations of two of Chinua Achebe's novels, Things Fall Apart (1994[1959]) and Arrow of God (1969[1964]), to the Portuguese translations of these texts. It aims at identifying semantic variations of appraisal in the retranslations as well as testing the retranslation hypothesis originated in Berman (1990). According to theoretical assumptions in this text, the translation of a literary text would be an "incomplete" act that could only achieve completion through retranslations. Previous works on translation of literary texts do not usually investigate appraisal from a discourse-semantics perspective, disregarding it in unfolding texts and using a corpus analysis methodology. Dias (2018) draws on a discourse-semantics model to study Brazilian translations as re-instantiations. This work focuses on excerpts of the Portuguese reinstantiations Tudo se desmorona (2008), from Things Fall Apart, and A flecha de Deus (1979), from Arrow of God. The study uses appraisal analysis as a method to investigate patterns of evaluative configurations of attitude, engagement and graduation in the excerpts studied. The findings, compared to those in Dias (2018), suggest there are semantic variations between the pairs of re-instantiations regarding the appraisal mode, the different coupling and commitment of values, and non-re-instantiations or the instantiation of new values. These results suggest the two reinstantiations are different types of paraphrases of the source text. They also confirm the retranslation hypothesis.
\end{abstract}

Keywords: Semantic variations; Appraisal; Re-instantiation; Retranslation; Things Fall Apart; Arrow of God. 


\section{Introdução}

Estudos empíricos sobre variações semânticas em traduções, ou reinstanciações, da perspectiva da semântica-discursiva, são recentes. Tais estudos tiveram enfoques ou corpora variados. Alguns deles investigaram a VALORAÇÃo, entre outros recursos linguísticos, em corpora de textos literários, valendo-se da metodologia de corpus (ROSA, 2008; VANDEPITTE et al., 2011; MUNDAY, 2012; DIAS; MAGALHÃES, 2017).

Outros estudos usam a análise da vALORAÇÃo em estudos da tradução com uma nova orientação. Souza $(2010,2013)$ propõe um modelo para investigação de reinstanciações, com enfoque na VALORAÇÃo, aplicado a textos jornalísticos traduzidos do inglês para o português. Chang (2017) investiga a reinstanciação usando textos literários traduzidos do inglês para o chinês. Cristófaro (2018) e Dias (2018) adaptam o modelo de Souza (2010) para estudar a vALORAÇÃo em reinstanciações de narrativas literárias.

Esta investigação expande Dias (2018), que estudou as traduções brasileiras de Things Fall Apart (TFA) ${ }^{3}, O$ mundo se despedaça (2009[1983]) (MD), e de Arrow of God (AG), A flecha de Deus (2011) (FD_PB). O objetivo é estudar as variações semânticas de VALORAÇÃo em traduções portuguesas desses dois romances de Chinua Achebe para relacioná-las à retradução. A primeira tradução, Tudo se desmorona (TD), de 2008, publicada depois da citada tradução brasileira, é considerada retradução. A segunda, A flecha de Deus (FD_PE), de 1989, é considerada tradução, pois foi publicada antes da referida retradução brasileira. Os contextos sociais distintos em que foram realizadas e publicadas as traduções justificam sua escolha para as indagações propostas. Considerando-se a hipótese da retradução, indaga-se se as variações semânticas encontra-

${ }^{3}$ São usadas as iniciais dos textos para referir-se a eles ao longo do trabalho. Como as reinstanciações brasileira e portuguesa têm o mesmo título, A flecha de Deus, para distingui-las, usam-se as siglas FD_PB para a primeira e FD_PE para a segunda. 
das distinguem os pares de traduções enquanto paráfrase - texto "incompleto", ou mais distante - ou citação - texto "completo", ou mais próximo - do texto-fonte (TF). Indaga-se, especificamente, se há tendência à inscrição dos valores evocados de atitude e à contração da heteroglossia do TF nas duas reinstanciações e se há variação nesses traços nestas últimas entre si. Verifica-se, ainda, se há construções distintas de valores e de posicionamentos de leitura nos textos analisados.

As narrativas portuguesas fazem parte do Corpus de traduções e retraduções -RETRAD, um corpus paralelo de em torno de três milhões de palavras, compilado no Laboratório Experimental de Tradução e disponível em www.portalminas.letras.ufmg.br. Integram este corpus textos originais em inglês e suas (re)traduções em português brasileiro e europeu. Das referidas narrativas portuguesas, foram selecionados os mesmos excertos estudados em Dias (2018). A metodologia usada baseia-se em Martin e White (2005) no que se refere à anotação e classificação dos recursos do sistema de VALORAÇÃo nos textos. Baseia-se, ainda, em Macken-Horarik (2003) e Macken-Horarik e Isaac (2014), para a verificação dos padrões valorativos nas narrativas estudadas e para a síntese e explicitação da metodologia de pesquisa da VALORAÇÃo, respectivamente.

Este artigo está organizado em quatro seções, além desta Introdução e das Considerações Finais. A primeira apresenta a fundamentação teórica do trabalho, a segunda descreve os procedimentos metodológicos de seleção e de análise das narrativas, a terceira relata os resultados obtidos e a quarta os discute, levando em conta Dias (2018).

\section{Fundamentação teórica}

Nesta seção, faz-se uma resenha dos trabalhos teóricos que embasam este estudo. Abordam-se estudos que desenvolveram o sistema de VALORAÇão e relatam-se os trabalhos empíricos dos estudos da tradução que tomam o sistema de valoração como base para investigar a tradução como reinstanciação. 


\subsection{O sistema de valoração e a perspectiva de análise de gênero}

O sistema da VALORAÇÃo, de acordo com Martin e White (2005), é um sistema da metafunção interpessoal no nível do estrato semântico-discursivo da língua e está relacionado à sintonia, variável de registro, no âmbito da teoria linguística sistêmico-funcional (LSF). De acordo em esta teoria, o texto constrói três tipos de significado, denominados de metafunções. O significado ou metafunção interpessoal está relacionado à encenação das trocas intersubjetivas e dos posicionamentos de valor entre escritor e leitor. O significado ou metafunção ideacional refere-se à representação e/ou construção das experiências relativas aos mundos físico e psíquico do escritor. O significado ou metafunção textual é responsável por organizar os demais significados no texto de forma coesiva e coerente.

Martin e White (2005) definem a VALORAÇão através dos seus três principais domínios: a atitude, o comprometimento e a gradação. A atitude está relacionada com a expressão dos sentimentos, compreendendo reações emocionais pessoais, julgamentos de comportamentos e avaliação de coisas. O comprometimento está voltado para a fonte das atitudes e as vozes em jogo no discurso. A função da gradação é de graduar os valores de atitude, amplificando ou tornando as categorias indistintas.

A atitude inclui três regiões de sentimentos: o afeto, o julgamento e a apreciação. A região do afeto abrange os recursos usados para construir as diferentes reações emocionais dos indivíduos. A região do julgamento engloba os recursos usados para avaliar o comportamento das pessoas em relação a princípios normativos. A região da apreciação, por sua vez, compreende os recursos de construção da avaliação das coisas, como fenômenos naturais e semioses, seja como produto ou como processo. Os recursos atitudinais variam de acordo com a carga valorativa, podendo ser positivos ou negativos. Os recursos de atitude podem, ainda, ser realizados de modo inscrito (explícito) e de modo evocado (implícito), como é o caso de recursos cujo significado, a princípio, pode- 
ria ser experiencial, mas é colorido no texto por outro significado valorativo adjacente.

O comprometimento lida com recursos diversos da língua (da modalidade, entre eles) e o modo como estes recursos posicionam o falante ou escritor em relação aos valores construídos nos textos e em relação a respostas de ouvintes/leitores prospectivos àquela posição valorativa. Martin e White (2005) modelam os textos de acordo com sua capacidade de construir um grau maior ou menor de abertura para o diálogo com outras vozes. Assim, o comprometimento possibilita duas opções, a monoglossia e a heteroglossia. A monoglossia compreende as proposições que são afirmativas categóricas simples, nas quais o espaço para outras vozes é reduzido em grau maior. A heteroglossia integra recursos nas orações que significam uma abertura maior para outras vozes, dissonantes ou não. Como há diferentes graus dessa abertura, a heteroglossia permite as opções contrair e expandir, realizadas por uma série de recursos, entre eles, os de negação e da modalidade.

A gradação está relacionada com o potencial que as valorações têm de serem graduáveis. No caso dos recursos de atitude, inerentemente graduáveis, a gradação lida com o ajuste dos valores relativos aos sentimentos. Nesse caso, a gradação é de força e pode aumentar ou diminuir os valores expressos. As categorias definidas nesta subseção são reapresentadas na seção de metodologia, no Quadro 2.

Martin e White (2005) e Martin e Rose $(2007,2008)$ trabalham com os significados construídos em textos, portanto, seu modelo de língua integra o estrato do gênero. Gêneros, para os autores citados, são configurações de significados linguísticos ou de outras modalidades de linguagem, ou padrões globais recorrentes desses significados, os quais constituem os textos. Os gêneros têm um propósito social a ser atingido, por etapas, ao longo do desenrolar dos textos.

$\mathrm{O}$ enfoque deste trabalho é a narrativa. Alguns trabalhos realizados com base na perspectiva semântico-discursiva da linguística sistêmico-funcional dedicam-se à investigação da narrativa. Macken-Horarick (2003) estuda narrativas literárias escritas para um 
público infanto-juvenil. Seus resultados mostram que os recursos valorativos podem ter configurações distintas nas narrativas.

\subsection{VALORAÇão e tradução como reinstanciação}

Alguns trabalhos na área dos estudos da tradução examinam recursos valorativos em corpora de textos literários de tamanhos variados, usando programas computacionais de análise lexical de corpus; portanto, descontextualizando sua ocorrência das narrativas (ROSA, 2008; VANDEPITTE et al., 2011; MUNDAY, 2012; BLAUTH, 2015; DIAS; MAGALHÃES, 2017). Outros estudos realizam análise discursiva das traduções, baseados na vALORAÇÃo e afiliados ou à LSF ou aos estudos da tradução.

White (2016), no âmbito da LSF, enfoca diferentes traduções do excerto inicial do romance francês L'Étranger, de Camus, para o inglês. $\mathrm{O}$ autor conclui que diferenças entre escolhas de apenas um recurso valorativo nas traduções podem significar diferença do contexto social construído pelos textos. Conclui, ainda, que tal variação pode resultar em textos com carga valorativa distinta e potencial distinto para posicionar leitores prospectivos em relação a valores atitudinais. Qian (2012), no âmbito dos estudos da tradução, analisa exemplos, traduzidos do inglês para o chinês, de uma sessão de perguntas e respostas do discurso proferido pelo Vice-Presidente Cheney na Universidade de Fudan em 2004. Os achados mostram variações do valor de expansão para o valor de contração nos textos traduzidos (TTs), atribuídas seja a diferenças entre os dois sistemas linguísticos, seja à função do TT na cultura chinesa.

Para este estudo, foram de interesse os trabalhos recentes que investigam a tradução como reinstanciação na perspectiva de gênero relatada na primeira seção. Reinstanciação, para Martin (2006), é o processo pelo qual o potencial de significados de um dado texto é reconstruído em outro texto. O processo implica um movimento de distanciação, isto é, um movimento que tende a subir na escala de instanciação em direção a níveis em que significados mais gerais 
ou menos específicos estão disponíveis, e um movimento descendente na escala voltando aos níveis do texto.

Martin (2006) classifica três gêneros da classe de gêneros "história”, sobre uma batalha em Papua-Nova Guiné, como citação, paráfrase e recontagem. Na perspectiva semântico-discursiva de Martin, a instanciação modela as relações intertextuais em relação a um potencial de significado que é mais e menos compartilhado, dependendo do tipo de relação entre os textos. Na citação, estabelecem-se relações diretas de instância a instância no polo da instanciação com enfoque nas realizações, enquanto na paráfrase e na recontagem abre-se, em menor ou maior grau, respectivamente, para o potencial de significado generalizado, movendo-se em direção ao polo do sistema linguístico para reinstanciar o primeiro texto diferentemente. Martin (2006) sugere, por exemplo, que dois dos textos examinados constroem uma perspectiva relativamente objetiva do evento relatado e um posicionamento de leitura que distancia os leitores prospectivos. Já o terceiro texto constrói os participantes do evento como seres afetivos e um posicionamento de envolvimento e empatia com a história para os leitores prospectivos.

O termo "acoplamento", usado em relação aos três tipos de reinstanciações, refere-se a padronizações similares, repetidas em um texto, de realizações de dois ou mais sistemas. O acoplamento pode acontecer no âmbito das três metafunções ou entre elas, na instanciação e na reinstanciação dos textos, conforme Martin (2010). O termo "calibragem" refere-se à quantidade de potencial de significado que é demandada de qualquer sistema de significado no processo de instanciação (MARTIN, ibid.). Os significados não são apenas selecionados, mas acoplados (isto é, combinados) e calibrados (isto é, oferecidos em um determinado nível de especificidade ideacional ou interpessoal).

Souza (2013) adapta o modelo de Martin (2006, 2010) para a tradução, mostrando sua produtividade na análise de textos jornalísticos traduzidos. Os resultados encontrados nessa análise mostram que, de modo geral, o perfil das reinstanciações é similar ao perfil do texto-fonte. Entretanto, variações de acoplamento ou de 
calibragem de determinados valores reconstroem o texto-fonte de uma perspectiva distinta, seja em relação aos valores em si, seja em relação ao posicionamento de leitura ou ao investimento autoral na reconstrução desses valores.

Chang (2017) investiga duas traduções e duas adaptações de Pride and Prejudice, de Jane Austen, para o chinês, da perspectiva das metafunções ideacional e interpessoal. Seu enfoque foi a calibragem e o modo como o TF foi reinstanciado diferentemente nas traduções e adaptações. O trabalho mostra que as duas traduções, enquanto reinstanciações do TF, são mais próximas deste, ideacional e interpessoalmente. Já as duas adaptações calibram menos significados ideacionais e interpessoais que o TF, tendo em vista a redução de detalhes e projeções.

Cristófaro (2018) investiga padrões valorativos em excertos dos contos Eveline e The Dead, de James Joyce, e as variações semânticas em duas reinstanciações dos excertos. A autora identificou síndromes valorativas de afeto, julgamento e apreciação no TF e variações em acoplamentos de atitude nos TTs que implicaram variações em síndromes avaliativas nestes textos. Foram também identificadas síndromes valorativas nas quais houve consistente aumento de gradação nas reinstanciações. Adicionalmente, diferentes acoplamentos e calibragens da gradação foram responsáveis por grande parte das variações identificadas.

Dias (2018) investiga as traduções brasileiras de TFA e AG, realizadas pela mesma tradutora. De acordo com os resultados de Dias (2018), nos textos traduzidos (TTs) investigados, foram identificadas variações semânticas nos tipos e subtipos de VALORAÇão. As variações no modo de ativação identificadas em Dias (2018) mostram, de forma geral, a explicitação de valores de atitude nas reinstanciações estudadas. Uma tendência desse tipo de variação foi a explicitação de valores de atitude realizados por metáforas lexicais, por vezes um traço característico do TF. Na calibragem das proposições heteroglóssicas, Dias (2018) identificou principalmente a contração das proposições dialogicamente expansivas dos TFs. Ainda no comprometimento, as três únicas ocorrências de 
proposições do tipo proclamar dos TTs analisados foram reinstanciadas como proposições do tipo refutar ou como monoglossia. Nos resultados de Dias (2018), um traço distintivo entre os TTs foi a não reinstanciação de valores de atitude de um dos TFs e a instanciação de novos valores no outro TT. Enquanto em MD determinados valores de atitude não foram reinstanciados, em FD_PB, houve a instanciação de novos valores.

A teorização inicial sobre a retradução é atribuída a Berman (1990) e outros. De acordo com esta teorização, traduções de um texto literário, posteriores a uma primeira tradução, tenderiam a atingir sua completude. A hipótese da retradução, formulada a partir dessas reflexões, postula que a retradução seria mais próxima do original que a primeira tradução, mais distante. Fazendo um paralelo com a teorização de Martin (2006) sobre as relações intertextuais, pode-se dizer que as últimas traduções tenderiam a ser citações enquanto as primeiras tenderiam a ser paráfrases do texto-fonte ${ }^{4}$.

Papoloski e Koskinen (2010) e Alvstad e Rosa (2015) oferecem uma revisão extensiva de trabalhos sobre a retradução e concluem que há diversas questões envolvidas na retradução (mercado editorial, mudanças das convenções tradutórias, entre outras). Sugerem que há necessidade de investigação do tema pelo viés linguístico. Em concordância com essa sugestão, Magalhães e Blauth (2015) e Pagano (2017) investigam o uso de itálicos ou a projeção de falas, respectivamente, em retraduções de textos literários. As autoras obtêm resultados inconclusivos sobre a hipótese que as traduções mais recentes de um texto literário para uma mesma língua-alvo seriam mais próximas do TF.

Levando-se em consideração os estudos sobre a VALORAÇÃo relatados, verifica-se neste artigo se as variações nas traduções analisadas fazem o movimento de distanciamento em direção ao potencial generalizado de significados, resultando em paráfrase dos TFs,

\footnotetext{
${ }^{4}$ Enfatiza-se que, na recontagem, fica mais difícil de se identificar as relações intertextuais, com a possibilidade, em última instância, de ter-se a recontagem apenas se inspirada no primeiro texto (MARTIN, 2006).
} 
e se as retraduções fazem o movimento em direção a níveis mais específicos do significado, implicando relações diretas de instância a instância ou citação dos TFs.

\section{Metodologia}

Nesta seção, faz-se uma descrição dos procedimentos de seleção dos textos para o estudo e dos procedimentos de análise desses textos. Esses procedimentos estão apresentados nas subseções 3.1 e 3.2, respectivamente.

\subsection{Procedimentos de seleção dos textos}

Foram selecionadas as reinstanciações portuguesas de TFA e AG, de Chinua Achebe, para uma comparação com os resultados obtidos em Dias (2018) utilizando os mesmos TFs e duas reinstanciações brasileiras. A reinstanciação do primeiro TF, TD, foi traduzida por Eugénia Antunes e Paulo Rêgo e publicada pela Editora Mercado de Letras Editores em 2008, de Lisboa. A reinstanciação do segundo TF, FD_PE, foi traduzida por Maria Helena Morbey e publicada pela Edições 70 em 1979, também de Lisboa. Foram selecionados, ainda, excertos das reinstanciações portuguesas equivalentes àqueles utilizados nas análises de Dias (2018).

Há um hiato temporal de 25 anos entre TD e $\mathrm{MD}^{5}$ e de 32 anos entre as duas traduções de AG, o que pode indicar mudança nas convenções tradutórias. $\mathrm{O}$ fato de haver essa probabilidade de mudança nas convenções de tradução entre os pares de reinstanciações e o fato de poderem ser tomadas como (re)traduções ${ }^{6}$ foram motivações para a comparação, neste caso baseada na VALORAÇão. Nes-

${ }^{5}$ MD, entretanto, foi publicada em 2009 , tendo passado por um processo de revisão mínimo, conforme Dias (2018).

${ }^{6}$ Ainda que publicadas no Brasil e em Portugal, são consideradas retraduções em consonância com a literatura sobre o tema. 
te estudo, MD é considerada a tradução e TD a retradução de TFA, bem como FD_PE é a tradução e FD_PB a retradução de AG.

Um resumo de TFA e AG foi apresentado em Dias (2018), bem como informações sobre MD e FD_PB. Informações sobre TD podem ser encontradas em Souza (2015). Sobre FD PE, recorreu-se aos paratextos para informações. Esta publicação oferece aos seus leitores prospectivos uma biografia resumida do autor de AG e uma resenha sobre a obra. Além disso, registra em uma lista de nomes e breve identificação de todos os personagens, além de um glossário com a tradução das palavras do Ibo usadas no TF.

\subsection{Procedimentos de análise}

Para a análise da atitude, foram utilizados os procedimentos conforme descritos em Macken-Horarik e Isaac (2014), que sistematizam os procedimentos básicos facilitadores da análise da VALORAÇÃo abordados por Martin e Rose (2007[2003]) e Martin e White (2005). Esses procedimentos incluem:

- A identificação das avaliações inscritas, juntamente com a fonte e o alvo da avaliação, seguida da identificação das avaliações evocadas e da ocorrência de recursos de gradação.

- A descrição da carga valorativa, dos níveis de força e dos contrastes nas escolhas de gradação.

- O mapeamento de síndromes de escolhas em contraste uns com os outros.

- A codificação dos itens identificados de acordo com as categorias específicas do sistema de VALORAÇÃo (ver a seção 2 deste artigo).

- A comparação das escolhas de valoração dos diferentes textos em análise, para verificação de semelhanças e diferenças nessas escolhas e sua ocorrência ou não nas narrativas, além de identificação de padrões específicos do gênero e sua função. 
Os códigos usados para a anotação foram adaptados daqueles sugeridos em Martin e White (2005). O Quadro 1 ilustra essa codificação.

Quadro 1 - Códigos de anotação da análise da atitude.

\begin{tabular}{|l|l|l|l|l|l|}
\hline Código & Significado & Código & Significado & Código & Significado \\
\hline felic. & felicidade & tenac. & tenacidade & força(+) & aumentando \\
\hline satis. & satisfação & prop. & propriedade & força(-) & diminuindo \\
\hline segur. & segurança & verac. & veracidade & foco(+) & enfocando \\
\hline inclin. & inclinação & reac. & reação & foco(-) & desfocando \\
\hline norm. & normalidade & comp. & composição & - & - \\
\hline capac. & capacidade & val. social & valor social & - & - \\
\hline
\end{tabular}

Fonte: Adaptado de Martin e White (2005, p. 71).

A análise da VALORAÇÃo foi baseada nas categorias do Quadro 2, a seguir. Cabe ressaltar que essas categorias estão devidamente definidas na seção 2 .

Quadro 2 - Organização da rede de sistemas de vaLORAÇÃo.

\begin{tabular}{|l|l|l|l|}
\hline $\begin{array}{l}\text { Rede de } \\
\text { sistemas }\end{array}$ & $\begin{array}{l}\text { Tipos de } \\
\text { VALORAÇão }\end{array}$ & $\begin{array}{l}\text { Subtipos de } \\
\text { VALORAÇão }\end{array}$ & $\begin{array}{l}\text { Tipos de } \\
\text { heteroglossia }\end{array}$ \\
\hline \multirow{4}{*}{ VALORAÇão } & \multirow{3}{*}{ Atitude } & Afeto & - \\
\cline { 3 - 4 } & \multirow{3}{*}{ Comprometimento } & Julgamento & - \\
\cline { 3 - 4 } & & Apreciação & - \\
\cline { 2 - 4 } & & Monoglossia & - \\
\cline { 2 - 4 } & \multirow{2}{*}{ Gradação } & Foreçaglossia & Contrair \\
\cline { 3 - 4 } & & & Expandir \\
\hline
\end{tabular}

Fonte: Adaptado de Martin e White (2005). 
Os procedimentos para a análise incluíram a identificação e classificação: 1) do tipo de comprometimento de cada proposição dos textos; 2) de instâncias valorativas, com sua carga valorativa e modo de ativação; e 3) de recursos de gradação. A identificação e classificação de cada categoria foi feita em cada par de texto-fonte e texto traduzido, que foram previamente alinhados por sentenças (critério grafológico) em planilhas eletrônicas do Google Sheets. A Figura 1 ilustra o modelo da planilha usada para a análise de atitude e a Figura 2 a planilha do comprometimento.

Figura 1 - Tela capturada da planilha de atitude.

\begin{tabular}{|c|c|c|c|c|c|c|c|c|c|c|c|c|c|}
\hline Texto-fonte & Texto traduzido & Item_valorativo_TF & Item_valorativo_TT & Avaliador_TF & $=$ Avaliador_TT & Afeto_TF & Julgamento_T & & Apreciaçăo_tF & Afeto_TT & Julgamento_ & TT & Apreciação_TT \\
\hline $\begin{array}{l}\text { Okonkwo was well } \\
\text { known throughout the } \\
\text { nine villages and even } \\
\text { beyond. }\end{array}$ & $\begin{array}{l}\text { Okonkwo era bem } \\
\text { conhecido nas nove } \\
\text { aldeias e mesmo para lá } \\
\text { delas. }\end{array}$ & well known & bem conhecido & narrador & narrador & - & $(+)$ norm. & - & - & - & (+)norm. & . & - \\
\hline \multirow{2}{*}{$\begin{array}{l}\text { His fame rested on solid } \\
\text { personal achievements. }\end{array}$} & \multirow{2}{*}{$\begin{array}{l}\text { A sua fama assentava } \\
\text { em sólidas conquistas } \\
\text { pessoais. }\end{array}$} & fame & fama & narrador & narrador & . & $(+)$ norm. & . & . & . & (+)norm. & . & . \\
\hline & & $\begin{array}{l}\text { solid personal } \\
\text { achievements }\end{array}$ & $\begin{array}{l}\text { sólidas conquistas } \\
\text { pessoais }\end{array}$ & narrador & narrador & 一 & (+)capac. & • & r & $\checkmark$ & (+)capac. & 一 & 一 \\
\hline \multirow{3}{*}{$\begin{array}{l}\text { As a young man of } \\
\text { eighteen he had brought } \\
\text { honor to his village by } \\
\text { throwing Amalinze the } \\
\text { Cat. }\end{array}$} & \multirow{3}{*}{$\begin{array}{l}\text { Aos dezoito anos de } \\
\text { idade honrara a sua } \\
\text { aldeia ao derrotar } \\
\text { Amalinze, o Gato. }\end{array}$} & honor & honrara & narrador & narrador & . & (+)norm. & v & v & . & (+)norm. & v & - \\
\hline & & throwing & derrotar & narrador & narrador & . & (+)capac. & - & . & . & (+)capac. & . & . \\
\hline & & the Cat & - Gato & narrador & narrador & . & (+)capac. & . & . & . & (+)capac. & . & v \\
\hline \multirow{2}{*}{$\begin{array}{l}\text { Amalinze was the great } \\
\text { wrestler who for seven } \\
\text { years was unbeaten, } \\
\text { from Umuofia to Mbaino. }\end{array}$} & \multirow{2}{*}{$\begin{array}{l}\text { Amalinze era o grande } \\
\text { lutador que durante sete } \\
\text { anos permanecera } \\
\text { invicto, desde Umuofia a } \\
\text { Mbaino. }\end{array}$} & the great wrestler & o grande lutador & narrador & narrador & - & (+)capac. & • & r & r & $(+)$ capac. & . & . \\
\hline & & unbeaten & invicto & narrador & narrador & . & (+)capac. & . & • & • & (+)capac. & . & . \\
\hline
\end{tabular}

Fonte: Elaborado pelos autores.

Ressalta-se que, devido à extensão horizontal da planilha, não foi possível capturar as colunas de todas as categorias da atitude. Na planilha, há ainda colunas para o modo de ativação, o avaliado e a gradação.

Figura 2 - Tela capturada da planilha de comprometimento.
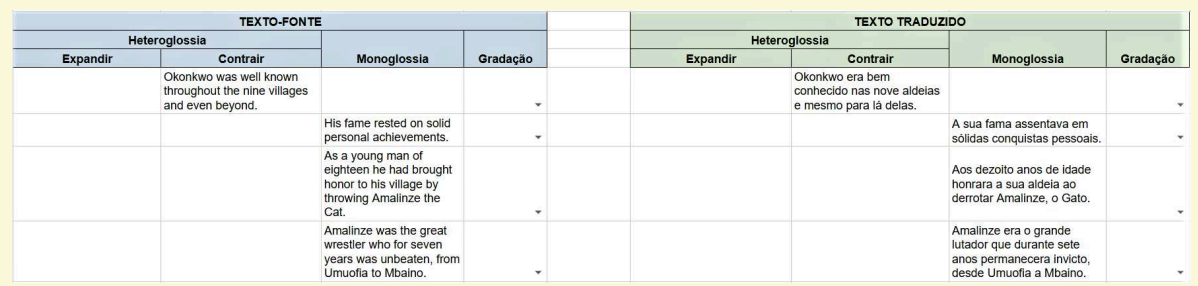

Fonte: Elaborado pelos autores. 
Nesse modelo de análise do comprometimento, as proposições são distribuídas topologicamente nas colunas de acordo com o tipo de comprometimento. Sublinha-se que as duas planilhas foram elaboradas com base nos modelos manuais apresentados em Martin e White (2005). Após as classificações das categorias, procedeu-se à comparação entre as análises de cada par de textos para a identificação de variações no acoplamento e/ou na calibragem dos tipos de VALORAÇão.

Examinar as opções de cada um dos tipos de afeto, julgamento e apreciação não estava previsto como procedimento metodológico. No entanto, devido à relevância de um dos achados, foi necessário acrescentar níveis de especificidade de afeto. As opções de afeto são "felicidade", "segurança", "satisfação" e "inclinação", conforme ilustrado no Quadro 3.

Quadro 3: Tipos de afeto

\begin{tabular}{|l|l|}
\hline Tipo de atitude & Tipos de afeto \\
\hline \multirow{4}{*}{ Afeto } & Felicidade \\
\cline { 2 - 2 } & Segurança \\
\cline { 2 - 2 } & Satisfação \\
\cline { 2 - 2 } & Inclinação \\
\hline
\end{tabular}

Fonte: Adaptado de Martin e White (2005).

A "felicidade" reúne os valores relativos às "coisas do coração" (MARTIN; WHITE, 2005, p. 49), como "amar” e "odiar”. A "segurança" lida com os valores de estabilidade e instabilidade emocional, como "calmo" e "nervoso". A "satisfação" está relacionada à compleição ou não de metas, como "satisfeito" e "insatisfeito". Por fim, a "inclinação" engloba as expressões de medo e desejo em relação a coisas e situações prospectivas, como "querer" e "recear". 


\section{Resultados}

Esta seção está organizada em três subseções. Na primeira, são apresentados exemplos de variações que ocorreram nas reinstanciações brasileiras e portuguesas em uma mesma oração do TF. $\mathrm{Na}$ segunda subseção, apresentam-se exemplos de variações que ocorreram nas reinstanciações brasileiras e portuguesas, mas em diferentes orações do TF. Por fim, a terceira subseção é dedicada ao relato descritivo dos tipos de variações que foram distintivos entre as reinstanciações portuguesas e brasileiras.

\subsection{Variações semânticas nas mesmas orações}

A análise contrastiva entre os textos-fonte e suas reinstanciações portuguesas e brasileiras ${ }^{7}$ permitiu identificar a ocorrência de variações semânticas nas mesmas orações ou complexos oracionais. Em alguns dos casos, não somente ocorreram na mesma oração como também foram relativas aos mesmos valores atitudinais e ao mesmo tipo de variação semântica.

Os exemplos nos quais as variações semânticas foram identificadas são apresentados ao longo desta subseção. Usa-se a fonte na cor vermelha para destacar os itens específicos em que as variações semânticas ocorreram.

Os Exemplos 1 e 2 apresentam ocorrências de variação no modo de ativação de valores atitudinais. Trata-se do mesmo tipo de variação: um valor atitudinal de julgamento implícito foi explicitado nas reinstanciações.

Exemplo 1:

TFA: As a young man of eighteen he had brought honor to his village by throwing Amalinze the Cat. Amalinze was the great wrestler who for seven years was unbeaten, from Umuofia to Mbaino.

${ }^{7}$ Ressalta-se que as análises das reinstanciações brasileiras aqui apresentadas foram obtidas em Dias (2018).

Cad. Trad., Florianópolis, v. 38, n 3, p. 319-351, set-dez, 2018 
TD: $\quad$ Aos dezoito anos de idade honrara a sua aldeia ao derrotar Amalinze, o Gato. Amalinze era o grande lutador que durante sete anos permanecera invicto, desde Umuofia a Mbaino.

MD: Aos dezoito anos, trouxera honra à sua aldeia ao vencer Amalinze, o Gato, um grande lutador, campeão invicto durante sete anos em toda a região de Umuófia a Mbaino.

Exemplo 2:

AG: It brought down the harmattan as well, and each new day made the earth harder so that the eventual task of digging up whatever remained of the harvest grew daily.

FD_PE: O harmatão deixara também de soprar, e, dia após dia, a terra tornava-se mais sólida, de forma que a eventual tarefa de desenterrar o que restasse das colheitas se tornava diariamente mais difícil.

FD_PB: Esse temporal trouxe também o harmatã, e a cada dia a terra se tornava mais dura. Consequentemente, seria cada vez mais difícil escavá-la para retirar os inhames.

No Exemplo 1, o valor de julgamento sobre a personagem é realizado por léxico não atitudinal (throwing) e é mais dependente do contexto para que seu valor atitudinal seja ativado. Em outras palavras, esse valor de julgamento foi realizado de modo evocado, implícito. Em TD e MD, as escolhas lexicais (derrotar e vencer) explicitam o valor de julgamento da personagem, uma vez que isoladamente já é possível interpretar que se trata de um comportamento humano e que tem carga valorativa positiva. No Exemplo 2, o valor de apreciação negativa da tarefa em AG foi instanciado no complexo oracional em destaque e também não é realizado por léxico atitudinal, ou seja, o valor foi realizado implicitamente. Nas reinstanciações, o uso do atributo "difícil” explicita o valor de apreciação negativa da tarefa. 
O próximo exemplo ilustra variação de acoplamento da gradação. Determinados valores atitudinais que são intensificados no TF foram reinstanciados sem o acoplamento de gradação. O movimento inverso também foi identificado: um valor que não acopla gradação no TF foi reinstanciado com intensificação.

Exemplo 3:

AG: At any other time Ezeulu would have been more than a match to his grief.

FD_PE Em qualquer outra ocasião, Ezeulu não teria sofrido tanto.

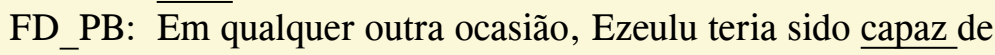
suportar sua dor.

No Exemplo 3, foram identificados no TF dois valores atitudinais, um de julgamento (more than a match) e outro de afeto (his grief). O primeiro valor é intensificado pelo recurso more than e o segundo sem intensificação. Em FD_PE, além de o valor de julgamento não ter sido reinstanciado, o valor de afeto foi intensificado com o uso do recurso "tanto". Em FD_PB, os dois valores foram reinstanciados, mas o valor de julgamento não acopla gradação, ou seja, não é intensificado.

Nos Exemplos 4 e 5, que seguem, são apresentadas ocorrências de variação no comprometimento das proposições. Em um dos exemplos, identificou-se o mesmo tipo de variação nas duas reinstanciações do mesmo TF.

Exemplo 4:

TFA: The hole would not let a man through.

TD: $\quad$ O buraco não era suficientemente grande para permitir a passagem de um homem.

MD: $\quad$ O buraco não era suficientemente grande para dar passagem a um homem. 
Exemplo 5:

AG: $\quad$ Of course he had lived to such a great age that his blindness became like an ornament on him.

FD_PE: Na verdade, o avô atingira uma idade tal que a cegueira se tornara como que um ornamento.

FD_PB: [Ø] Seu avô vivera até uma idade tão avançada que sua cegueira tornou-se uma espécie de ornamento.

No Exemplo 4, uma proposição heteroglóssica do tipo expandir em TFA (uso do modal would) foi reinstanciada como uma proposição do tipo contrair com o uso da negação (não) na oração. Conforme a VALORAÇÃO, os modais constroem o grau de probabilidade de determinada proposição e estão calcados na intersubjetividade dos falantes/escritores, portanto, são dialogicamente expansivos. Nas duas reinstanciações, a proposição foi reinstanciada como proposição negativa, sem o uso de modal.

No Exemplo 5, houve diferentes tipos de variação. A proposição de TFA, com o uso do recurso Of course, foi instanciada como heteroglossia do tipo contrair. Ao usar o referido recurso, o narrador do TF não somente investe autoralmente nos valores da proposição como também pressupõe que seu leitor prospectivo provavelmente compartilha do mesmo posicionamento. Em FD_PE, essa proposição foi reinstaciada com o uso de outro recurso ( $\mathrm{Na}$ verdade), que não realiza a mesma função do recurso do TF. Em FD_PB, a proposição heteroglóssica de TFA foi reinstanciada como uma proposição monoglóssica. Com isso, o narrador da reinstanciação brasileira excluiu o provável compartilhamento daqueles valores pelo leitor prospectivo.

Além dessas variações, ainda nas mesmas orações, foram identificadas outras ocorrências de variação nas reinstanciações brasileiras. No Exemplo 1, um novo valor de atitude foi instanciado (campeão) em MD. No Exemplo 3, a reinstanciação de a match como "capaz" (FD_PE) resultou na explicitação dos valores de atitude, ambos do tipo julgamento. 


\subsection{Variações semânticas em diferentes orações}

As mesmas siglas e destaques usados para a identificação nos exemplos da subseção precedente são usados nesta subseção. São apresentados quatro exemplos das referidas variações semânticas. Os tipos de variação são distintos e mostram, ao mesmo tempo, escolhas linguísticas que resultam em variação semântica e escolhas que não resultam em variação.

Exemplo 6:

TFA: He was tall and huge, and his bushy eyebrows and wide nose gave him a very severe look.

TD: $\quad$ Era alto e largo e as suas espessas sobrancelhas e nariz largo emprestavam-lhe um ar muito severo.

MD: $\quad$ Era um homem alto, grandalhão, a quem as sobrancelhas espessas e o nariz largo davam um ar extremamente severo.

No Exemplo 8, identifica-se uma variação de calibragem da gradação. O valor de apreciação de TFA (huge) se encontra em um ponto mais elevado na escala de intensificação se comparado a big, que já possui algum grau de intensidade. Em TD, a reinstanciação de huge como "largo" não calibra o mesmo grau de intensificação, ou seja, a gradação do valor de apreciação foi reduzida. Em MD, a escolha por "grandalhão" reinstanciou o valor de apreciação e o grau de intensidade do referido valor de TFA.

Exemplo 7:

AG: He was now an old man but the fear of the new moon which he felt as a little boy still hovered round him.

FD_PE: Embora já bastante idoso, o medo da Lua nova ainda pairava à sua volta, tal como acontecera na sua juventude.

FD_PB: Hoje, ele estava velho, mas o temor da lua nova que sentira quando menininho não o abandonara. 
No Exemplo 7, a reinstanciação portuguesa apresenta duas ocorrências de variação, uma no acoplamento do comprometimento e a outra no acoplamento da gradação. Em AG, a primeira oração $(H e$ was now an old man) foi instanciada como uma proposição monoglóssica, portanto, sem a abertura do espaço dialógico a vozes discursivas alternativas. Em FD_PE, a proposição de AG foi reinstanciada como uma proposição heteroglóssica do tipo contrair com o uso de um recurso de concessão (embora). Com isso, o narrador da reinstanciação portuguesa, mesmo rejeitando as vozes discursivas alternativas, abriu o espaço dialógico para incluí-las. Em FD_PB, a referida proposição do TF foi reinstanciada com o mesmo tipo de comprometimento. Além disso, em FD_PE, também foi identificado o acoplamento de gradação a um valor atitudinal (bastante velho) que não é intensificado em AG.

Passando ao último exemplo desta subseção, pode-se identificar em TD outra variação no modo de ativação de determinado valor atitudinal. Trata-se também de um exemplo de explicitação de um valor de atitude.

Exemplo 8:

TFA: "We cannot bury him. Only strangers can. We shall pay your men to do it. When he has been buried we will then do our duty by him. We shall make sacrifices to cleanse the desecrated land."

TD: - Não podemos enterrá-lo, apenas os estranhos o podem fazer. Pagaremos esse trabalho aos teus homens. Depois do enterro, trataremos do nosso dever fazendo sacrifícios para purificar a terra profanada.

MD: - Nós não podemos enterrá-lo; só estranhos podem fazê-lo. Estamos dispostos a pagar a seus homens para que façam isso. E então, depois que ele tiver sido enterrado, cumpriremos nosso dever para com o morto. Faremos sacrifícios, a fim de limpar a terra profanada. 
Em TFA, o valor de julgamento positivo foi realizado por uma palavra de conteúdo experiencial (cleanse), que provavelmente depende da relação estabelecida com outros valores atitudinais explícitos (sacrifices e desecrated) para que seu valor atitudinal seja ativado. Em TD, interpretou-se que a escolha lexical "purificar" já permite, mesmo isoladamente, a identificação de um comportamento humano positivo. Em MD, o valor de atitude também foi realizado por conteúdo experiencial, como ocorre em TFA.

Antes de finalizar esta subseção, é importante sublinhar que esses são somente alguns dos exemplos das ocorrências de variação semântica identificadas nas reinstanciações. Cabe também ressaltar que, embora nessas orações as variações tenham ocorrido somente em uma das reinstanciações, são tipos de variações que foram identificados tanto nas reinstanciações portuguesas quanto nas brasileiras.

\subsection{Traços distintivos entre as reinstanciações portuguesas e brasileiras}

Nesta subseção, são apresentados exemplos de tipos de variação que ocorreram somente nas reinstanciações portuguesas. No Quadro 4, apresenta-se uma síntese dos tipos de variação e indica-se em qual das reinstanciações cada tipo de variação foi identificado.

Quadro 4 - Tipos de variação de valoRAÇão.

\begin{tabular}{|l|l|l|}
\hline Tipo de variação & TD & FD_PE \\
\hline Acoplamento de atitude (julgamento-afeto) & - & \\
\hline Acoplamento de atitude (apreciação-julgamento) & - & \\
\hline Calibragem de afeto & - & \\
\hline Não reinstanciação de afeto & - & \\
\hline Não reinstanciação de julgamento & - & \\
\hline
\end{tabular}

Fonte: Elaborado pelos autores. 
De acordo com o disposto no Quadro 4, observa-se que os cinco tipos de variação semântica distintivos ocorreram na mesma narrativa, FD_PE. Um ponto a ser ressaltado é que todos esses tipos de variação semântica são relativos ao domínio da atitude. Os exemplos são apresentados na sequência de acordo com a ordem em que os tipos de variação aparecem no Quadro 4.

Em relação ao primeiro tipo de variação semântica disposto no Quadro 4, foram identificadas duas ocorrências de variação. Apresenta-se aqui um dos exemplos.

Exemplo 9:

AG: Whenever they shook hands with him he tensed his arm and put all his power into the grip, and being unprepared for it they winced and recoiled with pain.

FD_PE: Sempre que o cumprimentavam com um aperto de mão, tornava o braço tenso e usava de tal força que os jovens, não suportando a dor, se retraíam e retiravam apressadamente a mão.

O Exemplo 9 ilustra uma ocorrência de variação de acoplamento da atitude em FD_PE. Um valor de julgamento de AG foi reinstanciado como valor de afeto. Enquanto em AG constrói-se um valor acerca do comportamento das pessoas (desprecavidas), na reinstanciação portuguesa, constrói-se a infelicidade dos avaliadores, o sofrimento delas.

O segundo tipo de variação ocorreu no acoplamento de atitude. Identificou-se que um valor de apreciação do TF foi reinstanciado como valor de julgamento em FD_PE.

Exemplo 10:

AG: $\quad$ The moon he saw that day was as thin as an orphan fed grudgingly by a cruel foster-mother.

FD_PE: A Lua que ele viu naquele dia era tão débil como um órfão mal alimentado por uma cruel mãe adoptiva. 
No Exemplo 10, ao usar o atributo thin, o narrador do TF constrói um valor de apreciação da lua. Na reinstanciação portuguesa, considerou-se que o atributo "débil" constrói um valor de julgamento (debilidade, fraqueza) da lua. Assim interpretado, em FD_PE, há, ainda que localmente, uma construção da lua como portadora de um atributo que expressa comportamento humano.

O terceiro tipo de variação se refere à calibragem de afeto. As escolhas linguísticas do narrador de FD_PE reconstroem o mesmo valor de atitude (afeto), mas resultam em variação no subtipo de afeto.

Exemplo 11:

TF: $\quad$ Ezeulu did not like to think that his sight was no longer as good as it used to be and that some day he would have to rely on someone else's eyes as his grandfather had done when his sight failed.

FD_PE: Ezeulu recusava-se a admitir que a sua vista não era já tão boa como antigamente e que algum dia teria que confiar aquela missão nos olhos de outrem, à semelhança do que acontecera com o seu avô quando a vista lhe falhara.

No Exemplo 11, o valor de afeto construído no TF é do subtipo felicidade e foi realizado em uma proposição de negação. Em FD_PE, ao escolher "recusava-se" para reinstanciar o valor de afeto do TF (did not like), o narrador construiu a desinclinação (indisposição) afetiva da personagem Ezelu em lugar da negação de felicidade. Essa escolha linguística também resultou em variação no acoplamento do comprometimento, já que uma proposição heteroglóssica do TF foi reinstanciada como proposição monoglóssica.

Na sequência, apresenta-se um exemplo de não reinstanciação de um valor de afeto. Além dessa variação, há outra de acoplamento do comprometimento. 
Exemplo 12:

AG2: It lay on the ground in the grip of the joy.

FD_PE: Apesar de tudo permanecia [Ø].

Em AG no Exemplo 12, é possível identificar a ocorrência de um valor de afeto explícito (the joy). A realização desse valor de afeto positivo no TF funciona para criar um paradoxo com outro valor de afeto negativo, realizado pelo pronome $I$, que presume o grupo nominal the fear de uma oração anterior. Em FD_PE, o narrador não reinstancia o valor de afeto positivo e, consequentemente, não reconstrói, nessa oração, a relação paradoxal entre os valores de afeto. Além disso, a proposição de FD_PE foi reinstanciada como proposição do tipo contrair.

Ainda com relação à não reinstanciação de valores de atitude, em FD_PE, foi identificada uma ocorrência na qual um valor de julgamento do TF não foi reinstanciado. Essa ocorrência é apresentada no Exemplo 13.

Exemplo 13:

AG: $\quad$ And while it played its game the Chief Priest sat up every evening waiting.

FD_PE: E, entretanto, [Ø] o Sacerdote Supremo esperava todas as noites pacientemente.

No que tange ao Exempo 13, identificou-se que no TF played its game realiza um valor de julgamento. Trata-se de uma metáfora lexical que se refere à lua, que, no desenrolar da fase discursiva da qual o complexo oracional faz parte, é construída como enganosa, comportamento tipicamente humano. Essa metáfora lexical não é reinstanciada em FD_PE nem seu referido valor de julgamento. 


\section{Discussão dos resultados}

Nesta seção, busca-se responder às perguntas de pesquisa antecipadas na Introdução deste trabalho, com base nos resultados apresentados na seção precedente. As perguntas específicas referem-se às variações de VALORAÇÃo e a pergunta mais global à hipótese da retradução. Em relação a essa hipótese, os resultados deste estudo são relativizados, uma vez que as narrativas não foram analisadas integralmente. Esses resultados também são discutidos em comparação com os resultados das pesquisas empíricas resenhadas na fundamentação teórica deste artigo.

$\mathrm{Na}$ primeira pergunta, questiona-se se os valores evocados de atitude tendem a ser explicitados nas reinstanciações. Além disso, se os textos considerados como "tradução" e "retradução" têm comportamentos distintos entre si quanto a esse tipo de variação.

Tanto em TD quanto em FD_PE, foram identificadas ocorrências de explicitação de valores de atitude. Em TD, as três ocorrências de variação no modo de ativação foram de explicitação de valores evocados do TF (Exemplo 1, 2 e 8), corroborando os resultados de Dias (2018). Em FD_PE, as variações no modo de ativação foram equilibradas, ou seja, em metade das ocorrências, os valores de atitude foram explicitados e, na outra metade, os valores foram reinstanciados no modo implícito, corroborando parcialmente os resultados de Dias (2018). Ao comparar os pares de reinstanciação (tradução e retradução), identifica-se que a explicitação de valores de atitude não é um traço distintivo entre MD e TD.

Quanto à comparação entre FD_PE e FD_PB, nas duas reinstanciações, foram identificadas ocorrências tanto de valores atitudinais evocados que foram realizados como inscritos quanto de valores inscritos que foram evocados. A diferença entre elas é que em FD_PB, além de haver uma ocorrência a mais de variação, há mais ocorrências de inscrição (explicitação) do que de evocação dos valores. Esse poderia ser considerado um traço distintivo entre FD_PE e FD_PB pelo critério das variações no modo de ativação dos valores de atitude. 
A segunda pergunta inquire se as reinstanciações tendem à contração dialógica das proposições do TF e se esse tipo de variação também permite distinguir a "tradução" da "retradução". Em TD, identificou-se uma proposição do tipo expandir de TFA que foi reinstanciada como uma proposição do tipo contrair (Exemplo 4). O movimento contrário (proposição do tipo contrair reinstanciada como proposição do tipo expandir) não foi identificado. Os resultados de TD corroboram, pois, parcialmente os achados de Hong (2012) e Dias (2018). Em FD_PE, foram identificadas mais ocorrências de contração dialógica das proposições (Exemplos 5, 7 e 12) do que em TD. Essas ocorrências podem ser caracterizadas como tendência da reinstanciação de FD_PE e corroboram os resultados de Hong (2012) e Dias (2018).

No que diz respeito à distinção entre os textos considerados como "tradução" e "retradução", as variações no comprometimento não se mostram um traço distintivo. Tanto em MD e TD quanto em FD_PE e FD_PB, os tipos de variação e os números de ocorrências foram aproximados entre os pares de reinstanciações. Algumas das variações no comprometimento foram identificadas nas mesmas proposições e as escolhas dos tradutores foram iguais em alguns dos exemplos.

A terceira indagação é se as reinstanciações constroem valores e/ou posicionamentos de leitura distintos em relação ao TF e entre si. De acordo com os resultados, na reinstanciação portuguesa de $\mathrm{AG}$, quatro tendências de variação contribuem para a construção da narrativa de uma perspectiva mais afetiva tanto em relação ao TF quanto à reinstanciação brasileira. As tendências são: não reinstanciação de valores de julgamento (Exemplos 13 e 3), reinstanciação de valores de julgamento como valores de afeto (Exemplo 9), redução da intensificação dos valores de julgamento (Exemplo 3) e intensificação dos valores de afeto (Exemplo 3).

Embora, na reinstanciação brasileira de AG tenham sido identificadas ocorrências de redução da intensificação de valores de julgamento, não há ocorrências de não reinstanciação de valores de julgamento nem variação de atitude em que um valor de julgamento 
tenha sido reinstanciado como valor de afeto. Com isso, considera-se que as variações em discussão têm o potencial de construir um posicionamento de leitura distinto de FD_PE, corroborando os achados de Martin (2006) e Souza (2013). Além disso, a intensificação dos valores de afeto e as não reinstanciações de determinados valores foram traços distintivos entre a "tradução" e "retradução", corroborando, respectivamente, os achados de Cristófaro (2018) e Dias (2018) quanto ao papel desses tipos de variação na distinção entre as reinstanciações.

No que concerne às reinstanciações de TFA, não foram identificadas em TD variações semânticas que tenham o potencial de construir perspectivas distintas nem posicionamentos de leitura distintos em relação a TFA. Nesse quesito, TD pode ser considerada mais próxima ao seu TF. Quanto a MD, segundo as análises de Dias (2018), determinadas variações nos valores de atitude têm o potencial de construir diferentes perspectivas acerca de algumas personagens. Além disso, Dias (2018) identificou que variações no modo de ativação e a instanciação de novos valores de atitude em MD também atribuíram maior ou menor proeminência aos valores de julgamento que incidem sobre algumas personagens.

A análise discursiva permitiu identificar qual das reinstanciações investigadas apresentou maior número de variações semânticas. MD apresentou, no geral, maior número de variações (15) que TD (13), concentrando-se o maior número de acoplamentos na atitude (6 para MD e 2 para TD) e o maior número de acoplamentos na gradação (5 para TD e 2 para MD). FD_PE teve maior número de variações semânticas (29) do que FD_PB- (23), apresentando o maior número de acoplamentos de atitude (10 para FD_PE e 6 para FD_PB).

Uma vez que os resultados mostram a ocorrência de variações semânticas na reinstanciação de determinadas instâncias valorativas dos TFs, as reinstanciações investigadas podem ser classificadas como paráfrases das narrativas. No entanto, com base nas diferentes variações entre cada par de reinstanciação, é possível sugerir que as duas reinstanciações do mesmo TF se localizam em diferentes pontos de um contínuo entre paráfrase e citação. Nesse contínuo, uma 
das reinstanciações de cada um dos TFs se aproxima mais do TF que a outra. Os resultados mostram, pois, tendo em vista um contínuo, que ambas são paráfrases e que aquelas que se distanciam mais dos dois TFs são as traduções. Esses achados corroboram a hipótese de retradução (BERMAN, 1990), segundo a qual a tradução pode ser considerada mais "distante" do TF do que a retradução.

\section{Considerações finais}

Este artigo expandiu a análise de Dias (2018) das reinstanciações brasileiras para uma investigação das reinstanciações portuguesas de excertos de dois romances de Chinua Achebe, Things Fall Apart e Arrow of God. A proposta foi estudar as variações semânticas de VALORAÇão nessas reinstanciações e examinar tais variações à luz da hipótese da retradução. Foram elaboradas duas perguntas gerais de pesquisa, indagou-se se as variações semânticas de VALORAÇÃo encontradas diferenciavam os pares de traduções enquanto paráfrase ou citação do texto-fonte e se confirmavam a hipótese da retradução.

Essas indagações foram motivadas pelos resultados obtidos no estudo de Dias (2018) em relação às reinstanciações brasileiras. Achados de outros estudos empíricos tais como Souza (2010, 2013), White (2016), Chang (2017) e Cristófaro (2018) constituíram também pressupostos da pesquisa realizada. Os trabalhos citados constituíam um avanço em relação a outros como Rosa (2008), entre outros, de análise mais local, das escolhas lexicais nas traduções, por apresentar uma análise discursiva das traduções baseada na perspectiva teórico-metodológica da VALORAÇão de Martin e White (2005), entre outros.

As perguntas propostas foram respondidas e os objetivos atingidos. A análise discursiva, portanto, restrita a excertos dos romances, permitiu identificar, com base nesses excertos, qual das reinstanciações investigadas apresentou maior número de variações semânticas. Foi possível estabelecer um paralelo entre os tipos de reinstanciação 
de Martin (2006) e a hipótese da retradução de Berman (1990). Os resultados da análise permitiram identificar qual das reinstanciações de cada narrativa poderia ser categorizada como citação, paráfrase ou recontagem do TF. As variações encontradas não permitem considerar qualquer uma delas como citação ou recontagem do original, aproximando-se ou distanciando-se deste, respectivamente, enquanto instância, em direção ao potencial de significados. Permitem, entretanto, em um contínuo entre citação e paráfrase, considerar as duas reinstanciações como tipos distintos de paráfrase do TF, apresentando as traduções mais variações do que as retraduções. Assim como para as reinstanciações de TFA, para as reinstanciações de AG, o texto considerado como tradução, por constituir-se como paráfrase em um grau maior, se "distancia" mais do TF do que o texto considerado como retradução, o que corrobora a hipótese de retradução. Em trabalhos futuros, pode-se integrar mais excertos dos romances estudados para se testar os resultados aqui encontrados.

\section{Referências}

ACHEBE, C. A flecha de Deus. Tradução de Maria Helena Morbey. Lisboa: Edições 70, 1979.

. Arrow of God. 2. ed. New York: Anchor Books, 1989.

. Tudo se desmorona. Tradução de Eugénia Antunes e Paulo Rêgo. Lisboa: Mercado de Letras Editores, 2008.

. O mundo se despedaça. Tradução de Vera Queiroz da Costa e Silva. São Paulo: Companhia das Letras, 1983.

. Things fall apart. New York: Anchor Books, 1994.

Cad. Trad., Florianópolis, v. 38, no 3, p. 319-351, set-dez, 2018 
. O mundo se despedaça. 2. ed. Tradução de Vera Queiroz da Costa e Silva. São Paulo: Companhia das Letras, 2009.

. A flecha de Deus. Tradução de Vera Queiroz da Costa e Silva. São Paulo: Companhia das Letras, 2011.

ALVSTAD, C.; ROSA, A. Voice in Retranslation: An Overview and some Trends. Target, Amsterdam, v. 27, n. 1, p. 3-24, 2015.

BERMAN, A. La retraduction comme espace de la traduction. Palimpsestes, Paris, v. 4, p. 1-7, 1990.

BLAUTH, T. A paisagem indizível em duas traduções brasileiras de Heart of Darkness: uma análise de estilo com base em corpus. 2015. 138 f. Dissertação (Mestrado em Linguística Aplicada) - Faculdade de Letras, Universidade Federal de Minas Gerais, Belo Horizonte, 2015.

CHANG, C. Modelling translation as re-instantiation. Perspectives, Londres, v. 25, n. 1, p. 1-14, 2017.

CRISTÓFARO, N. Variações semânticas em duas reinstanciações de Eveline e The dead para o português: um estudo baseado no sistema da VALORAÇÃo. 2018. 224 f. Dissertação (Mestrado em Linguística Aplicada) - Faculdade de Letras, Universidade Federal de Minas Gerais, Belo Horizonte, 2018.

DIAS, C. VALORAÇÃo e Variações Semânticas: um estudo das reinstanciações de estágios discursivos de Things Fall Apart e Arrow of God. 2018. 150 f. Dissertação (Mestrado em Linguística Aplicada) - Faculdade de Letras, Universidade Federal de Minas Gerais, Belo Horizonte, 2018.

DIAS, C.; MAGALHÃES, C. Intervenção tradutória em textos literários: um estudo da apresentação da fala e da avaliação. Belas Infiéis, Brasília, v. 6, n. 1, p. 103-122, 2017.

MACKEN-HORARIK, M. Appraisal and the special instructiveness of narrative. Text, Adelaide, v. 2, n. 23, p. 285-312, 2003. 
MACKEN-HORARIK, M.; ISAAC, A. Appraising Appraisal. In: THOMPSON, G; ALBA-JUEZ, L. (Ed.). Evaluation in context. Amsterdam; Philadelphia: John Benjamins Publishing Company, 2014. p. 67-92.

MAGALHÃES. C.; BLAUTH, T. Estilo do tradutor: um estudo do uso do itálico, palavras estrangeiras e itens culturais específicos por seis tradutores de Heart of Darkness. In: VIANA, V.; TAGNIN, S. (Org.). Corpora na tradução. São Paulo: Hub Editorial, 2015. p. 171-209.

MARTIN, J. Genre, ideology and intertextuality: a systemic functional perspective. LHS, Sheffield, v. 2, n. 2, p. 275-298, 2006.

. Semantic variation: modelling system, text and affiliation in social semiosis. In: BEDNAREK, M.; MARTIN, J. R. (Org.). New Discourse on Language: Functional Perspectives on Multimodality, Identity, and Affiliation. Londres; New York: Continuum, 2010. p. 1-34.

MARTIN, J.; ROSE, D. Working with discourse: meaning beyond the clause. 2. ed. London: Continuum, 2007.

. Genre relations: mapping culture. Londres: Equinox, 2008.

MARTIN, J.; WHITE, P. The Language of Evaluation: Appraisal in English. New York: Palgrave MacMillan, 2005.

MUNDAY. J. Evaluation in translation: critical points of translator decisionmaking. London and New York: Routledge, 2012.

PAGANO, A. A contextual approach to translation equivalence. In: LAVIOSA, S. et al. Textual and contextual analysis in empirical translation studies. Singapore: Springer, 2017. p. 73-128.

PAPOLOSKI, O.; KOSKINEN, K. Reprocessing texts: the fine line between retranslating and revising. Across Languages and Cultures, Budapest, v. 11, n. 1, p. 29-49, 2010. 
QIAN, H. Investigating translator's positioning via the Appraisal Theory: a case study of the Q\&A part of a speech delivered by the U.S. Vice President Cheney. Sino-US English Teaching, New York, v. 2, n 9, p. 1775-1787, 2012.

ROSA, A. Narrator Profile in translation: work-in-progress for a semi-automatic analysis of narratorial dialogistic and attitudinal positioning in translated fiction. Linguistica Antverpiensia, Antwerp, n. 7, p. 227-248, 2008.

SOUZA, C. Itens lexicais estrangeiros como traço estilístico em things fall apart: um estudo em corpus paralelo. Belas Infiéis, Brasília, v. 4, n. 1, p. 39-52, 2015.

SOUZA, L. Interlingual re-instantiation: a model for a new and more comprehensive systemic functional perspective on translation. 2010. $339 \mathrm{f}$. Tese (Doutorado em Língua Inglesa) - Departamento de Língua e Literatura Estrangeiras, Universidade Federal de Santa Catarina, Florianópolis, 2010.

. Interlingual re-instantiation: a new systemic functional perspective on translation. Text\&Talk, Berlin, v. 33, n. 4/5, p. 575-594, 2013.

VANDEPITTE. S; VANDENBUSSCHE, L.; ALGOET, B. Travelling certainties: Darwin's doubts and their Dutch translations. The translator, London, v. 11, n. 2 , p. 275-299, 2011.

WHITE, P. Constructing the "Stranger" in Camus' L'Etranger: registerial and attitudinal variability under translation. The Journal of Translation Studies, Seoul, v. 17, n. 4, p. 1-32, 2016.

Recebido em: 11/05/2018

Aceito em: 27/07/2018

Publicado em setembro de 2018

Célia Maria Magalhães. E-mail: celiamag@gmail.com ORCID: https://orcid.org/0000-0002-8494-6084

Cliver Gonçalves Dias. E-mail: cliver.dias@gmail.com

ORCID: https://orcid.org/0000-0003-4629-8415 